\title{
TREES AND WIND: A PRACTICAL CONSIDERATION OF THE DRAG EQUATION VELOCITY EXPONENT FOR URBAN TREE RISK MANAGEMENT
}

\section{By Scott Cullen}

\begin{abstract}
Arborists and urban foresters are increasingly concerned with tree risk management. The aerodynamic drag equation is a potentially useful management tool. Some sources question the form of equation-specifically, the velocity exponent-that should be applied to trees. For the tree risk manager, concerned with public safety and legal liability, this is more than an academic curiosity. Uncertainty about the appropriate exponent questions the reliability of the conventional form. This paper reviews the literature, reports on modeling of both equation forms, and concludes that the conventional form-velocity squared-is appropriate for trees. Detailed analysis is presented for the researcher or advanced practitioner. A summary explanation is provided for the typical practitioner.
\end{abstract}

Key Words. Aerodynamics; biomechanics; drag equation; trees and wind; tree risk management; velocity exponent; wind.

\section{INTRODUCTION Background}

Internationally, arborists and urban foresters are increasingly concerned with tree risk management (e.g., Matheny and Clark 1994; Coder 1996; Jim and Liu 1997; Wessolly and Erb 1998; Lonsdale 1999; Pokorny 2003). In an urban or landscape setting, the principal risk is personal injury or property damage caused by trees. In traditional forestry, by contrast, the principal risk is economic crop loss (e.g., Coutts and Grace 1995; Peltola et al. 2000). In either case, a key issue is the risk of structural failure of trees. Arborists and urban foresters have long recognized that risk of failure may be dependent on wind force, load, or drag. A number of sources in the arboriculture and urban forestry literature have applied biomechanics to tree failure (e.g., Sinn and Wessolly 1989; Mattheck and Breloer 1994; Coder 2000; James 2003a), and this growing awareness of biomechanical analysis has offered the possibility of actually quantifying the wind force on a tree crown. A relatively few sources in the arboriculture and urban forestry literature present the aerodynamic drag equation (e.g., Sinn and Wessolly 1989; Mattheck and Breloer 1994, p. 138; Alaoui et al. 1999). These are very brief treatments and do not enable informed application of the drag equation. Mattheck and Breloer (1994) even suggest that the drag equation cannot be reliably applied to trees. Fortunately, arborists and urban foresters can look to a much wider range of tree-wind literature from traditional forestry and other fields (Cullen 2002b). Cullen (2002a) reviewed these sources in order to support a practical application of the drag equation to an urban tree. There is heightened interest in North America (Brudi 2004) in methods that rely on the drag equation, and such methods are used routinely by European consultants (see, e.g., Brudi and van Wassenaer 2002).

\section{The Drag Equation}

Equation 1 is a generalized, conventional form of the drag equation, where $F_{\text {WIND }}$ is the horizontal wind force; $\rho$ (rho) is the density of air; $V$ is wind velocity; $A$ is the area of the trunk and crown; and $C_{D}$ is a dimensionless drag coefficient. This conventional form is found widely in the scientific and engineering literature. It is explained in detail by Niklas (1992) and Vogel (1994). It is based, ultimately, on Newton's laws of motion (Vogel 1994, p. 89; Benson 2001c).

$$
F_{\text {WIND }}=\frac{\rho}{2}\left(V^{2}\right)(A)\left(C_{D}\right)
$$

\section{Table 1. Notation.}

\begin{tabular}{lll}
\hline$A$ & area & \\
$C_{D}$ & drag coefficient, dimensionless & see Equations $4-6$ \\
$F_{W I N D}$ & wind force, load, or drag & see Equation 1 \\
$q$ & dynamic pressure & see Equations $2-3$ \\
$\rho$ & rho, air density & taken as $1.2 \mathrm{~kg} / \mathrm{m}^{3}$ \\
$V$ & wind velocity or speed & \\
\hline
\end{tabular}

The particular arrangement of terms known as "dynamic pressure" is derived from Bernoulli's equation for fluids (Niklas 1992, pp. 429-430, 438; Vogel 1994, pp. 52-62, 81; Benson 2001a) and is shown in Equation 2.

$$
\text { Dynamic pressure }=\frac{\rho}{2}\left(V^{2}\right)
$$

Dynamic pressure is simply a force per unit area, often designated q (Sinn and Wessolly 1989; Vogel 1994, pp. 5963; Brudi and van Wassenaer 2002; ASCE 2003), found by Equation 3. In practice, pressure ( $q$ ) may be specified by building codes or design standards, which may be applicable to tree risk management (Cullen 2002a). 


$$
q=\frac{\rho}{2}\left(V^{2}\right)=\frac{\frac{F_{\text {WIND }}}{A}}{C_{D}}
$$

\section{The Velocity Exponent}

This conventional form of equation, using $V^{2}$, suggests that $F_{\text {WIND }}$ varies as the square of $V$. The wider literature review found, however, that a number of sources suggest $F_{\text {WIND }}$ on a tree varies more "linearly" with $V$ and that the velocity exponent approximates 1. Cullen (2003) addressed the question of the velocity exponent in the drag equation in a previous paper intended to provide feedback to researchers. The current paper, by contrast, is expanded and is intended to provide guidance to practitioners, particularly arborists and urban foresters.

\section{Need and Purpose}

The drag equation is a potentially useful tool in urban tree risk management. Arborists and urban foresters are concerned with public safety. If the convential form $\left(V^{2}\right)$ is, as suggested by some of the literature, less appropriate for trees than a "linear" form $(V)$, then the conventional form is likely to overstate $F_{\text {WIND }}$, leading to unnecessary tree removal. Conversely, if a "linear" form is not in fact valid, it is likely to understate $F_{\text {WIND }}$ and overstate tree safety. More importantly, in terms of the drag equation's potential in urban tree risk management, if it is used as a management tool and a managed tree fails, litigation can result. In this setting, the conventional form might be attacked simply because the literature seems to suggest the "linear" form. This is especially true under rules of evidence in the United States focusing on "scientific reliability" under the Daubert doctrine (see, e.g., Babitsky 2004). Questioning the credibility or reliability of the form of analysis may expose the practitioner and the client or employer to liability regardless of the actual quality or reliability of analysis. This prospect could discourage practical use of the drag equation in urban tree risk managment. The purpose of this paper is twofold:

- first, to consider whether the conventional form of drag equation using $V^{2}$ is appropriate for trees and to resolve the apparent cloud around the velocity exponent;

- second, to enable the practitioner to explain and support selection of the velocity exponent used in the drag equation.

Much of the paper addresses the first purpose. This technical material and analysis will primarily be interesting to the researcher or to the advanced pratitioner, particularly if a scientifically detailed defense of the conventional form, $V^{2}$, is required. The second purpose is fulfilled, more simply, by the conclusion and the summary explanations. The typical practitioner may be interested only in them.
Comprehensive explanation of the drag equation and application guidance are beyond the scope of this paper.

\section{MATERIALS AND METHODS}

This paper reports questions or suggestions about whether the velocity exponent should be 1 rather than the conventional 2 and associated explanations as found in the literature that applies the drag equation (Equation 1) to trees. Basic explanations of the drag equation are also reviewed. No field or laboratory tests of actual trees were conducted. The charting facility of Microsoft $\AA$ Excel 97 was used to model and compare curves of drag $\left(F_{\text {WIND }}\right)$ values found using Equation 1 with various velocity $(V)$ exponent and drag coefficient $\left(C_{D}\right)$ values and a constant, arbitrary area (A). Model curves of $F_{\text {WIND }}$ values found using Equation 1 with $V$ and $V^{2}$ and various $C_{D}$ values were also compared to curves of actual $F_{\text {WIND }}$ and $C_{D}$ values reported in the literature for a constant, actual $A$.

\section{RESULTS \\ Literature Sources for the "Linear" Case}

This subsection briefly reviews the sources that have observed or commented on a "linear" increase in tree-wind drag with velocity that may be associated with a velocity exponent of 1 . For the sake of clarity, their explanations are provided separately in the following subsection.

- Mayhead (1973) is perhaps the classically cited source. Working with conifer data originally developed by Fraser (1962) and Raymer (1962) in wind tunnel tests, he reported that "drag is found to vary linearly with windspeed $(U)$, and not with $U^{2}$." In fact, much earlier sources observed the same phenomenon.

- Sauer et al. (1951) measured the drag on small conifers in a wind tunnel and on larger conifers mounted on a truck. They reported that, for at least one tested tree, "drag is linear with velocity in the range shown." They found this result in agreement with even earlier work by Tirén (1926). In a related study, Lai (1955) measured the drag on broadleaved trees mounted on a truck. Lai cites Tirén's $(1926,1928)$ conclusion that "the exponent for the velocity is not constant with crown drag."

- Grace (1977, p. 90), citing the wind tunnel work of Fraser (1962) and Raymer (1962) on conifers, noted that "it might be expected ... that the force would increase with the square of velocity, but this was not the case. ... [T] he force is linearly related to windspeed (up to $\sim 25 \mathrm{~m} / \mathrm{s}$ [56 mph])."

- Bell et al. (1990) observed that "drag for trees becomes more nearly linearly proportional to $V$. ."

- Roodbaraky et al. (1994), citing Fraser (1962) and Mayhead (1973), observed that "there is some evidence to suggest that the drag of trees in winds is actually linearly proportional to velocity rather than velocity squared ..." 
- Vogel, citing Mayhead (1973), observed (1994, p. 121) that "the increase in drag [on a tree] was more nearly proportional to the first than to the second power of velocity" and (1996) that "drag [on a tree] increased with an exponent of less than $1(0.72)$ rather than the expected 2.0 up to a speed [of] $38 \mathrm{~m} / \mathrm{s}$, or $85 \mathrm{mph}$."

- Baker (1995), citing Mayhead (1973), Johnson et al. (1982), and Roodbaraky et al. (1994), observed that "there is some doubt as to whether tree drag varies in proportion in the square of the velocity ... or simply in proportion to velocity."

- Haritos and James (1996), citing Baker and Bell (1992), observe that the velocity exponent "may depart from the 'classical' value of 2 to a lower value closer to unity."

- Bonser and Ennos (1998), working with saplings in wind tunnel experiments, observed that "the strains measured in the stems of these plants show a nonlinear relationship with the square of windspeed." Such strains would be a function of wind force.

- Smiley et al. (2000) mounted trees on a truck and measured wind loads on the trees at various truck speeds. They reported that "[measured] wind resistance showed a linear increase with vehicle speed." A calculated regression line extrapolating their data beyond the range of $V$ tested was also "linear." They did not explicitly employ or consider the drag equation.

- Moore and Maguire (2002), citing Hoag et al. (1971), Mayhead et al. (1975), and Roodbaraky et al. (1994), observed that "there is some debate as to whether the relationship between drag force and wind speed is quadratic or linear."

Taken together, the independent observations (Tirén 1926, 1928; Sauer et al. 1951; Lai 1955; Fraser 1962; Raymer 1962; Mayhead 1973; Bonser and Ennos 1998; Smiley et al. 2000) and the repetitive citations of Mayhead (1973) and Mayhead et al. (1975) by others seem to have some weight.

\section{Explanations for the "Linear" Case}

The "linear" sources quite consistently explain that if the drag on a tree varies more "linearly" than would be expected using $V^{2}$, it is because trees are flexible rather than rigid bodies and effectively reduce $A$.

Sauer et al. (1951) observed that "most variation in drag force acting on tree crowns is due to their deformation" and noted similar indications in Tirén (1926). Lai (1955) observed that "for a flexible, porous body such as a tree crown, the area and porosity change constantly with dynamic pressure." As noted above, dynamic pressure is a function of velocity (see Equation 2). Mayhead (1973) noted that drag was found to vary linearly with windspeed because "as is to be expected with a tree, the projected frontal area varies with windspeed." Grace (1977) explained the linear relationship was observed because "at higher wind-speeds, the trees became streamlined, exposing less area to the wind." Bell et al. (1990) explained, "For a building, the drag ... is directly proportional to the square of the wind velocity. ... The ability of trees to streamline reduces the cross-sectional area of the tree ... and correspondingly the wind interception. Thus, the drag for trees becomes more nearly linearly proportional to V."

Roodbaraky et al. (1994) noted the linear phenomenon "would be expected, due to streamlining of the trees and branches." Vogel (1989; 1994, pp. 121-124; 1996) cited Mayhead (1973) in this regard and also detailed his own research showing that individual broadleaves and broadleaf clusters change their shapes under wind load. Bonser and Ennos (1998) observed that "since sapling trees are relatively flexible, they deform easily in airflows; the stem bends and the needles fold up." Moore and Maguire (2002) observed that "departure from the quadratic relationship [toward a linear one] can be explained by streamlining, ... which acts to reduce the crown frontal area."

Many sources, in addition to the "linear" ones, similarly acknowledge the reduction in drag resulting from flexibility and reduction in effective area (e.g., Heisler and DeWalle 1988; Sinn and Wessolly 1989; Hedden et al. 1995; Gardiner et al. 2000; Mattheck and Bethge 2000; Spatz and Bruechert 2000).

Vogel (1994, p. 115) has suggested the term "reconfiguration" to describe this reversible reduction in crown area to distinguish it from permanent deformation, which is a different result of tree-wind interaction (see Robertson 1987; Cullen 2002c). "Reconfiguration" is used throughout this paper to include actual reduction in $A$ as well as actual streamlining, which technically is an increase in the proportion of friction or skin drag relative to the proportion of form or profile drag (Grace 1977, p. 13; Niklas 1992, pp. 437438; Vogel 1994, pp. 96-97).

\section{Modeled $\boldsymbol{F}_{\text {WIND }}$ Curves}

Figure 1 illustrates the apparent question raised in the literature: whether the expected curve of $F_{\text {WIND }}$ values found using $V^{2}$ in Equation 1 or the curve of $F_{\text {WIND }}$ values found using $V$ in Equation 1 more accurately describes the change in tree-wind drag over increasing $V$.

The remaining modeled curves are presented in following sections to illustrate the discussion.

\section{DISCUSSION}

\section{Practitioners' Questions}

It is not entirely clear from the "linear" sources, particularly those merely citing the earlier independent studies, whether the "linear" observations are simply intended to describe the rate of change in drag over velocity, or the shape or slope of 


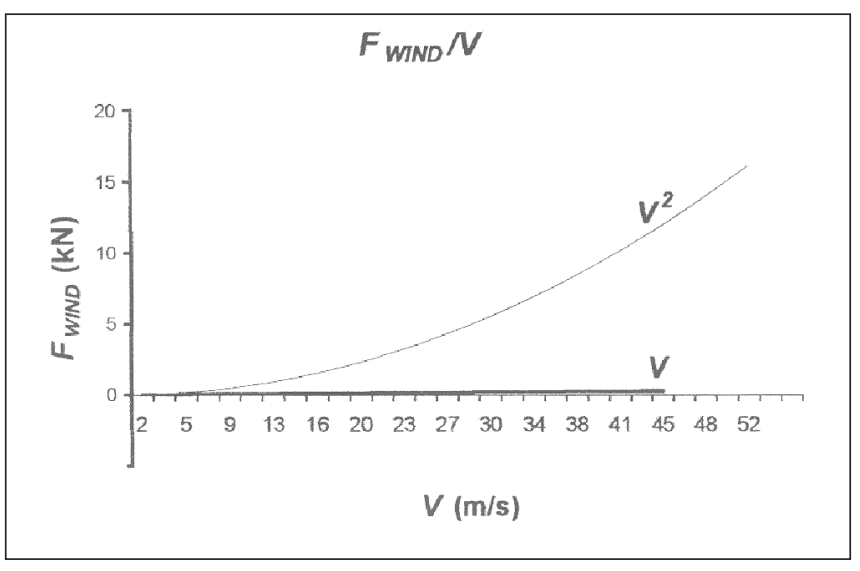

Figure 1. Curves of $F_{\text {WIND }}$ values found with Equation 1 using the conventional $V^{2}$ (the upper curve) and $V$ (the lower curve) with $\rho=1.2 \mathrm{~kg} / \mathrm{m}^{3}$, constant $A$ (here $\left.=10 \mathrm{~m}^{2}\right)$, and constant $C_{D}($ here $=1.0)$.

the drag curve (composed of a number of $F_{\text {WIND }}$ values estimated with the conventional form of drag equation for individual velocities), or to actually suggest that the conventional form of drag equation using $V^{2}$ should be discarded in favor of a form using $V$. The confusion is compounded because some of these sources employ the conventional form, $V^{2}$, in their own analyses even while explicitly questioning the exponent.

This raises practical questions:

- If the curve of actual $F_{\text {WIND }}$ values over a range of $V$ varies at some rate other than as the square of $V$, what is the best way to calculate $F_{\text {WIND }}$ values with Equation 1 ? The alternative choices are to vary the $V$ exponent, A or $C_{D}$.

- Would a curve of calculated $F_{\text {WIND }}$ values over a range of $V$, found with Equation 1 using $V^{2}$, be expected to vary purely as the square of $V$ as shown in Figure 1?

- Does the curve of actual $F_{\text {WIND }}$ values over $V$ vary "linearly," as some sources suggest, rather than with the square of $V$ ?

\section{Area (A)}

If, as acknowledged in the explanations above, the actual drag curve varies more "linearly" than with the square of $V$ because $A$ actually decreases as $V$ increases and the tree crown reconfigures, then it might seem most straightforward and most descriptive of the facts to vary $A$ with $V$. Hedden et al. (1995) suggest this approach. Peltola et al. (1999), Gardiner et al. (2000), and Gaffrey and Kniemeyer (2002) acually account for changes in area with velocity in their analyses of forest conifers. These are, however, exceptions.

Measuring or estimating these actual changes in $A$ on individual, urban trees would be a difficult practical exercise (Sinn and Wessolly 1989).
Even if data for variable $A$ are readily available, however, there is a procedural reason not to vary $A$. It is conventional in aerodynamic analysis to determine $A$ for $V=0$ and treat $A$ as a constant "reference area" as V increases (Vogel 1994, pp. 90-91; Benson 2001b, 2001d). Vogel (1994, p. 91) suggests that initial reference area should never be varied.

\section{The Drag Coefficient $\left(C_{D}\right)$}

The notion that the $V$ exponent determines the shape and slope of a curve of $F_{\text {WIND }}$ values, found with Equation 1, over a range of velocity (see Figure 1 ) seems to assume that $A$ and $C_{D}$ must be constant. Bonser and Ennos (1998) note that the "hypothesis is based on the naive assumption that trees do not deform and, hence, their drag coefficient remains constant." Niklas (2003) observes that this may be a common assumption. Mattheck and Breloer (1994, p. 81) explicitly consider $C_{D}$ a constant. In fact, $C_{D}$ is not constant with V (Sinn and Wessolly 1989; Niklas 1992, p. 438; Vogel 1994, p. 90). Mayhead (1973), the classically cited source for the "linear" argument, reported that actual $A$ is expected to decrease as $V$ increases. If reference $A$ (for $V=$ 0 ) remains constant in Equation 1 , then $C_{D}$ would also be expected to decrease as $V$ increases. Mayhead (1973) in fact found $C_{D}$ to decrease for all tested species, as shown in Figure 2. Ezquerra and Gil (2001) noted a "non-uniform" decrease with increasing $V$ in Mayhead's $C_{D}$ data. Gaffrey and Kniemeyer (2002) described a "parabolic decrease" in Mayhead's $C_{D}$ data.

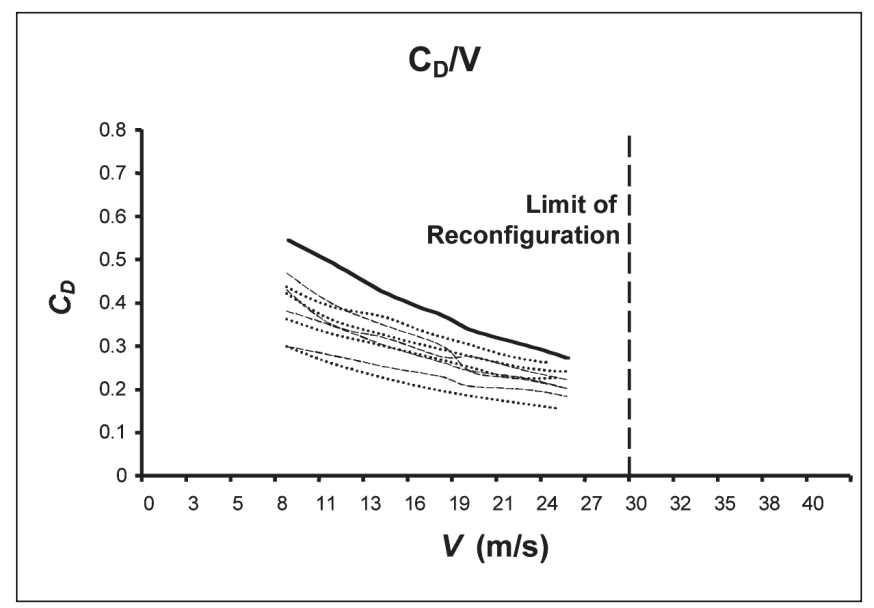

Figure 2. Mayhead's (1973) $C_{D}$ curves (here for various Pinus spp.) over the range of $V$ tested. Mayhead assumed the dashed vertical line would be the limit of crown reconfiguration and that $C_{D}$ would be constant beyond.

Grace (1977, p. 89) reported a similar pattern found by Raymer (1962). Kouwen and Fathi-Moghadam (2000) similarly found the friction factor (a dimensionless parameter used in hydrology and similar to $C_{D}$ ) of trees tested in water and air to decrease with increasing V. Sauer (1951), 
Lai (1955), and Bell et al. (1990) all similarly observed that a "linear" drag curve associated with a decreasing $A$ would alternatively be represented by a constant reference $A$ and a decreasing $C_{D}$.

Mayhead (1973) assumed $C_{D}$ to be constant only above velocities at which crown reconfiguration ceased and actual A became constant. Smiley (2000) acknowledged that the "linear" relationship of drag $\left(F_{\text {WIND }}\right)$ and $V$ (Smiley et al. 2000) was likely to cease beyond the range of crown reconfiguration. The curve of $F_{\text {WIND }}$ values found using Equation 1 with $V^{2}$, constant reference $A$ and decreasing $C_{D}$ over the range of crown reconfiguration is shown in Figure 3 and can be compared to the curves in Figures 1 and 6.

It is clear in Figure 3 that a curve of $F_{\text {WIND }}$ values found using Equation 1 with $V^{2}$, constant reference $A$, and decreasing $C_{D}$ over the range of crown reconfiguration would not be expected to vary purely as the sqaure of $V$ as shown in Figure 1. Stated another way, a curve of $F_{\text {WIND }}$ values found using Equation 1 with $V^{2}$, and constant reference $A$, will describe a curve of actual $F_{\text {WIND }}$ values for a tree that reconfigures if $C_{D}$ is appropriately varied over $V$.

Some sources acknowledge that actual $A$ and, hence, $C_{D}$ will be variable with $V$ but find this a confusing or problematic rather than an expected and useful phenomenon (e.g., Heisler and DeWalle 1988; Hedden et al. 1995). This is often related to limited data or particular goals, but it may be that biological researchers have an incomplete understanding of fluid mechanics tools like the drag equation (Vogel 1994, p. 399) or that the engineering reference literature offers little guidance on the complex geometry of biological shapes (Loudon 1999).

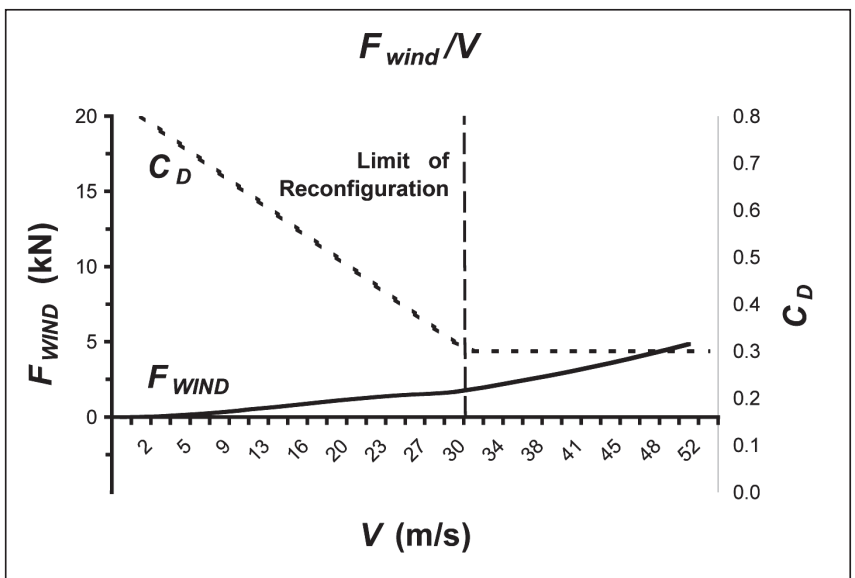

Figure 3. The lower curve shows $F_{\text {WIND }}$ values found with Equation 1 using the conventional $V^{2}$, with $\rho=$ $1.2 \mathrm{~kg} / \mathrm{m}^{3}, A$ constant (here $=10 \mathrm{~m}^{2}$ ), and $C_{D}$ decreasing over the range of crown reconfiguration but constant beyond the dashed vertical line as assumed by Mayhead (1973). The upper, dotted curve shows $C_{D}$ values used in Equation 1.
It is useful at this point to consider exactly what $C_{D}$ is $C_{D}$ represents the relationship of $F_{\text {WIND }}$ at any given $V, \rho$, and reference $A$-and an object or body with unique characteristics such as shape, porosity, flexibility or rigidity, texture, or orientation to the wind. $C_{D}$ simplifies the modeling of the complex interdependencies of these various characteristics (Vogel 1994, pp. 89-90; Benson 2001b).

Vogel (1994, pp. 89-91) explains that $C_{D}$ is "a dimensionless form of drag, the drag per unit area divided by the dynamic pressure." Recalling Equations 2 and 3, above, $C_{D}$ is thus defined by Equation 4 .

$$
C_{D}=\frac{\frac{\rho}{2}\left(V^{2}\right)}{\frac{\rho}{2}\left(V^{2}\right)}
$$

Sauer et al. (1951) call this relationship of drag and dynamic pressure a proportionality factor, and Bell et al. (1990) call it a ratio. Vogel further describes $C_{D}$ as the quality of "dragginess" as contrasted to the quantity of drag or $F_{\text {WIND }}$. In practice, $C_{D}$ is likely to be a function of $A$ rather than of unit area and represented by Equation $4 \mathrm{a}$.

$$
C_{D}=\frac{\frac{\rho}{2}\left(V^{2}\right)(A)}{\frac{\rho}{2}\left(V^{2}\right)(A)}
$$

Equations 4 and $4 \mathrm{a}$ at first seem confusing, as if a term is divided by itself. Vogel (1994, p. 89) explains that Equation 1 is "definitional" and merely allows conversion of $C_{D}$ to $F_{\text {WIND }}$ or $F_{\text {WIND }}$ to $C_{D}$. Grace (1977, p. 14) and Bell et al. (1990) explain that $C_{D}$ can be understood as a ratio of "actual" force and the force predicted by Equation 1 . Merging these explanations, $C_{D}$ can be understood as the ratio of actual and definitional forces as shown by Equation 5 and Table 2 .

$$
C_{D}=\frac{F_{\text {WIND-ACTUAL }}}{F_{\text {WIND-DEFINITIONAL }}}
$$

Table 2. Drag coefficient $\left(C_{D}\right)$ ranges.

\begin{tabular}{ll}
\hline If the actual and definitional forces are equal & $C_{D}=1.0$ \\
If the actual force is greater & $C_{D}>1.0$ \\
If the definitional force is greater & $C_{D}<1.0$
\end{tabular}

In other words, actual and definitional values for $F_{\text {WIND }}$ vary for many reasons, and such variations are reflected by $C_{D}$. Equation 6 is a generalized form of the equation used in practice (e.g., Mayhead 1973; Grace 1977, p. 14; Sinn and Wessolly 1989; Wood 1995; Grant and Nickling 1998; Kerzenmacher and Gardiner 1998). 


$$
C_{D}=\frac{F_{\text {WIND }}}{\frac{\rho}{2}\left(V^{2}\right)(A)}
$$

Understanding that Equations 1 and 6 are "definitional" and merely allow conversion of $C_{D}$ to $F_{\text {WIND }}$ or $F_{\text {WIND }}$ to $C_{D}$, it should now be clear that one of the terms must be known to solve for a value of the other. To solve Equation 1 for $F_{\text {WIND }}$ on a tree, an actual $C_{D}$ must be known for a tree with similar characteristics. To solve Equation 6 for $C_{D}$, an actual $F_{\text {WIND }}$ must have been found by experiment, for example in a wind tunnel (e.g., Mayhead 1973), on a moving vehicle (e.g., Sauer et al. 1951; Lai 1955; Hoag et al. 1971; Kouwen and Fathi-Moghadam 2000; Smiley 2000), or by direct field measurement (e.g., Roodbaraky et al. 1994; Grant and Nickling 1998).

\section{The Velocity (V) Exponent}

As shown in Figure 1, reducing the velocity exponent to 1 from the conventional 2 and treating $A$ and $C_{D}$ as constants results in a more "linear" curve of calculated $F_{\text {WIND }}$ values over velocity than would be expected using a velocity exponent of 2 and treating $A$ and $C_{D}$ as constants.

It is clear from the discussion of $A$ that actual $A$ may vary with $V$. While some analysts reflect variations in $A$ in the drag equation, such data may be problematic and, in any case, it is conventional to treat $A$ as a constant reference value. It is clear from the discussion of $C_{D}$ that if reference $A$ is constant and actual $A$ decreases over $V$, then $C_{D}$ also decreases over $V$ (see Figure 2). $C_{D}$ is intended to reflect changes in drag over $V$, so on this basis alone it seems more appropriate to use $V^{2}$ and a variable $C_{D}$ rather than $V$ and a constant $C_{D}$ to reflect a drag curve which is "more linear" than the curve expected using $V^{2}$ and a constant $C_{D}$.

Even if it is convenient or otherwise appealing to vary the exponent-say the analyst prefers a constant $C_{D}$ or wants to project a drag curve without having to solve Equation 1 iteratively for values of $F_{\text {WIND }}$-Figure 3 clearly shows that once reconfiguration ceases and both actual $A$ and $C_{D}$ become constant, the drag curve becomes "less linear." Recall Tirén's (1926; 1928) conclusion "that the exponent for the velocity is not constant with crown drag." Baker (1995, citing Roodbaraky 1994) similarly observed "that the form of [exponential] relationship might vary depending upon whether or not the tree is in leaf." If the exponent must be varied over the range of $V$ or seasonally or with type of tree, any perceived advantage as compared to varying $C_{D}$ for those characteristics is minimized.

In addition, while some applications may be interested in $F_{\text {WIND }}$ across a wide range of $V$, practical risk assessment is likely to be concerned with relatively high, "storm" velocities that are above the "linear" range of the drag curve

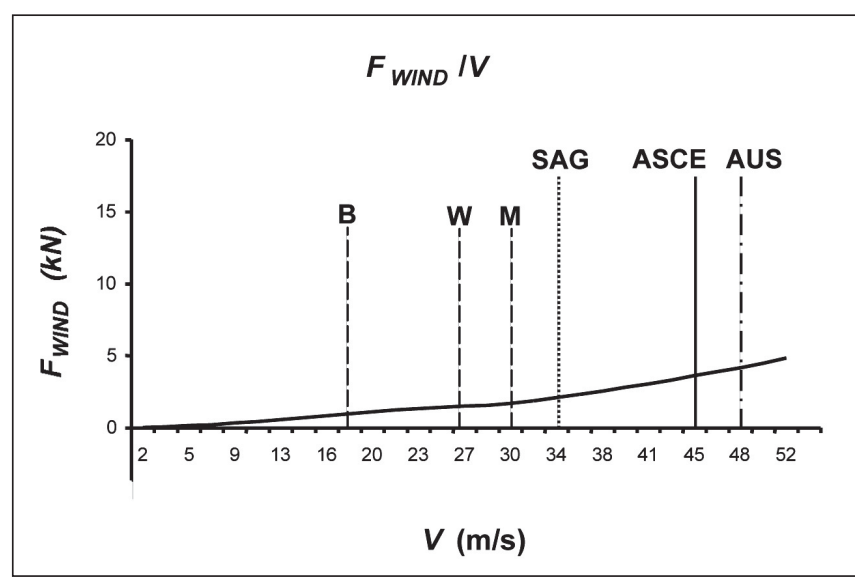

Figure 4. The curve of $F_{\text {WIND }}$ values found using Equation 1 with the conventional $V^{2}, \rho=1.2 \mathrm{~kg} / \mathrm{m}^{3}, A$ constant (here $=10 \mathrm{~m}^{2}$ ), and $C_{D}$ decreasing over the range of crown reconfiguration but constant beyond the dashed vertical line " $M$ " as assumed by Mayhead (1973). Wessolly (1995) suggests $C_{D}$ is constant beyond the dashed vertical line "W" ( 25-28 m/s). Brudi and van Wassenaer (2002, Figure 3) suggest there is little crown reconfiguration or decrease in $C_{D}$ beyond the dashed vertical line "B" $(\sim 17-21 \mathrm{~m} / \mathrm{s})$. The "hurricane" standard as applied by the SAG-

Baumstatik group is the dotted vertical line. The ASCE (U.S.) standard as applied by Cullen (2002a) is the solid vertical line. The Australian standard as applied by James (2003b) is the dashed-dotted vertical line. (Also see Figure 3.)

(Mayhead 1973). As shown in Figure 4, engineering standards which may be applied to tree risk assessment will be concerned with this higher range of $V$ (Standards Australia 1989; Wessolly 1995; ASCE 1999; Mehta and Perry 2001; Cullen 2002a; ASCE 2003; James 2003a). The "SAG-Baumstatik" group of consultants (referred to by Brudi and van Wassenaer, 2002) similarly consider stability at higher wind speeds. Niklas (2002) describes such "a priori specifications for tree safety" which will be in this higher range of $V$.

There are also compelling procedural reasons to use the conventional form, $V^{2}$ :

- First, the practioner is unlikely to develop $C_{D}$ data experimentally and will therefore look to the catalog of $C_{D}$ data available from the literature. It is now clear that $C_{D}$ is derived using Equation 6. Almost all of the reviewed sources describing some form of Equation 6 did so with the conventional form $V^{2}$, even if they noted the "linear" form of drag curve or questioned the $V$ exponent. (The exception was Roodbaraky et al. 1994. They tested both $V^{2}$ and $V$ forms of Equations 1 and 6 . Their "experiments did not lend support to the 
hypothesis that tree drag is proportional to $V$ rather than $V^{2}$, as has been previously suggested.") The practitioner is most likely to employ $C_{D}$ values derived using $V^{2}$. It should now also be clear that if $C_{D}$ is derived using $V^{2}$, it must also be applied using $V^{2}$. The requirement to derive and employ $C_{D}$ with the same $V$ exponent is reinforced by Figures 5 and 8 .

- Second, the conventional form, $V^{2}$, is found in dynamic pressure as shown in Equation 2. Where engineering standards or building codes that use a value of $q$ as shown in Equation 3 are applied to tree risk management (Sinn and Wessolly 1989; James 2003b; Cullen 2002a), it may be inappropriate or entirely inaccurate to vary the exponent. In addition, design wind velocities found in engineering standards (see Figure 3) are based on values of $q$ found using $V^{2}$.

- Third, using the nonconventional form, $V$, isolates the study and its data from the much broader catalog of data derived using the conventional form, $V^{2}$. This makes it difficult to compare studies, to rely on standard reference data, or to interface with other disciplines. Many reviewed sources relied on standard reference data as surrogates for or baseline comparisons with their own $C_{D}$ values. For example, Denny (1994) compared experimental $C_{D}$ values for a limpet shell in water to standard reference values for a flat plate, cylinder and sphere; Grant and Nickling (1998) compared tree $C_{D}$ values found experimentally to standard reference values for solid cylinders and cones of various sizes; Spatz and Bruechert (2000) conceptually contrasted a standard reference $C_{D}$ of 1.0 for a flat plate to that to be expected for a flexible tree; Niklas et al. (2002) used a standard reference $C_{D}$ of 1.0 for a cylinder in modeling drag for a columnar cactus; and Hygelund and Manga (2003) compared a standard reference $C_{D}$ of 1.0 for a cylinder to $C_{D}$ values found experimentally for model logs in water.

\section{Validity of the "Linear" Case}

As noted at the beginning of this discussion, whether the actual drag curve is truly "linear" (the lower curve in Figure 1 ) is a separate question from how to represent it. Ennos (1999) questions the "linear" proposition, especially the extrapolation from relatively small test trees to larger ones. Bonser and Ennos (1998) had noted that mature trees are relatively more inflexible than smaller ones. Ennos (1999) and Bonser (2001) both note the difficulties in testing mature trees at wind speeds above the range of crown reconfiguration. Shi-Igai and Maruyama (1988) similarly note that small flexible trees may be poor models for taller, stiffer trees. Assuming there is reconfiguration and drag reduction in flexible, foliated trees, the phenomenon may be less significant in trees without leaves. Lai (1955) noted that "trees in leaf ... offer 2 to 10 times greater aerodynamic drag." Roodbaraky et al. (1994) found a broadleaf $C_{D}$ approximately 4 times higher in leaf than out of leaf.

Re-analyzing the [unpublished conifer] data of Mayhead et al. (1975), Moore and Maguire (2002) reported an apparent $V$ exponent of 1.5. They also noted that "Hoag et al. (1971) found [for a broadleaf] that drag force was proportional to the 1.4 power of wind speed and assumed that the drag coefficient was 1.5." As already noted above, Vogel (1996) observed "an exponent of less than 1 (0.72) rather than the expected 2.0 up to a speed [of] $38 \mathrm{~m} / \mathrm{s}$, or 85 mph" in Mayhead's (1973) data. In a recent study of a simple, flexible fiber Alben et al. (2002) found that drag varied in proportion to $V^{4 / 3}$. Modeled curves of $F_{\text {WIND }}$ values found using Equation 1 with these various other values are compared in Figure 5. Modeling also showed that $F_{\text {WIND }}$ values found using Equation 1 with $V^{0.72}$ could be made to

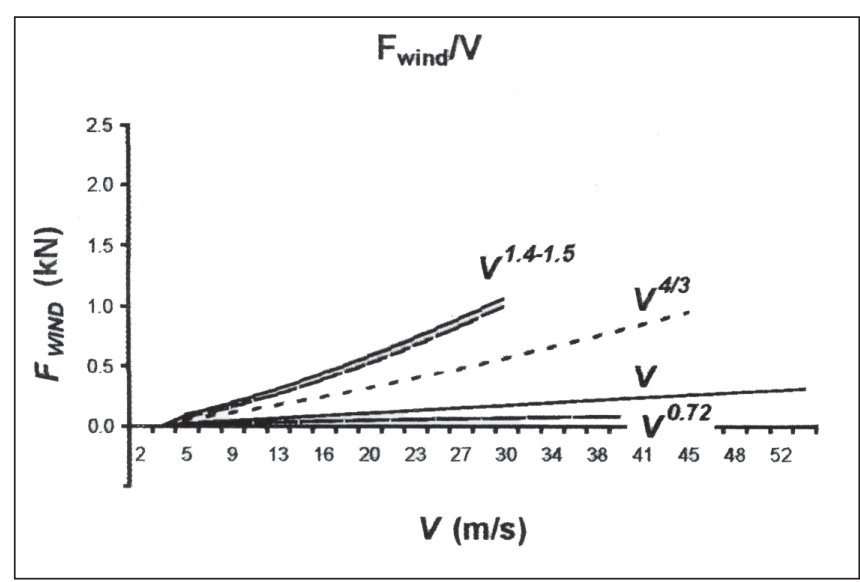

Figure 5. The upper curves of $F_{\text {WIND }}$ values found using $V^{1.5}$ with constant $A\left(\right.$ here $\left.=10 \mathrm{~m}^{2}\right)$ and $C_{D}($ here $=1.0)$ and $V^{1.4}$ with constant $A$ (here $\left.=10 \mathrm{~m}^{2}\right)$ and $C_{D}$ (here = 1.5) (Moore and Maguire 2002) are almost indistinguishable. The middle curve shows $F_{\text {WIND }}$ values found using $V^{4 / 3}$ (Alben et al. 2002) with constant $A$ (here = $\left.10 \mathrm{~m}^{2}\right)$ and $C_{D}($ here $=1.0)$. The lower curve shows $F_{\text {WIND }}$ values found using $V^{0.72}$ (Vogel 1996) with constant $A$ (here $\left.=10 \mathrm{~m}^{2}\right)$ and $C_{D}($ here $=1.0)$. A curve of $F_{\text {WIND }}$ values found using $V^{0.72}$ with constant $A\left(=10 \mathrm{~m}^{2}\right)$ can be fit to the upper curves using $C_{D}$ values varying from 1.5 to 17.5 over the range of $V$. The curve of $F_{\text {WIND }}$ values found using $V$ with constant $A\left(=10 \mathrm{~m}^{2}\right)$ and $C_{D}$ $(=1.0)$ from Figure 1 is shown for comparison.

NOTES:

1. The $F_{\text {WIND }}$ scale is changed from the earlier figures so that the curves can be distinguished.

2. The curves are limited to the ranges of $V$ reported.

3. The Alben et al. (2002) data were developed in soapy water rather than in air. The $V$ range shown here in air was converted from the reported range using $V_{\text {water }} \times 15$ (Vogel 1994, pp. 103-104). 
fit the curve of $F_{\text {WIND }}$ values found using Equation 1 with $V^{1.5}$ simply by manipulating $C_{D}$. It is not at all clear that the actual drag curve is "linear," meaning it should be described by using $V$ rather than $V^{2}$, or even what the various sources mean by "linear."

For summary comparison, the model drag curves from Figures 1, 3, and 5 are shown in Figure 6.

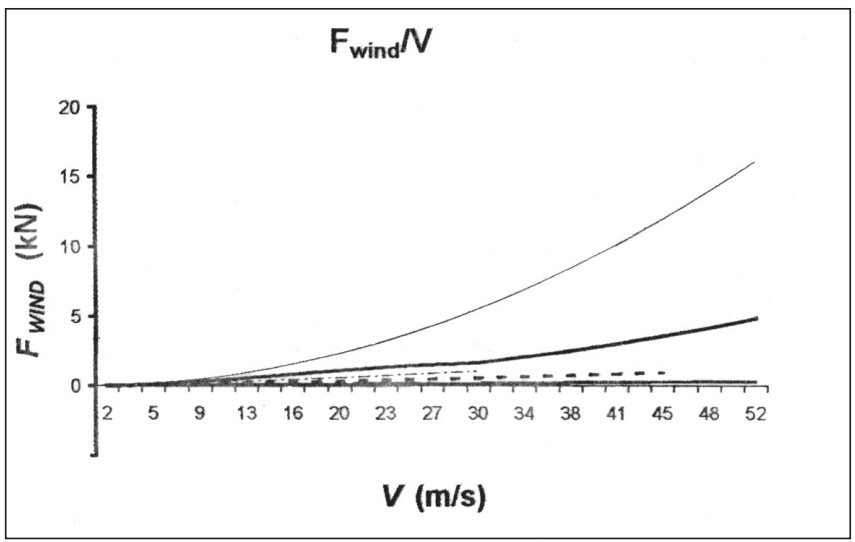

Figure 6. The drag curves from Figures 1, 3, and 5 are compared.

Grace (1977) presented curves of $F_{\text {WIND }}$ values found experimentally by Raymer (1962) and noted that "the force on the trees is linearly related to wind-speed above $10 \mathrm{~m} / \mathrm{s}$ [up to $\sim 25 \mathrm{~m} / \mathrm{s}$ ]." Grace also presented curves of $C_{D}$ values, which Raymer calculated from the experimental $F_{\text {WIND }}$ values using Equation 6 . The $C_{D}$ values declined over that range of $V$. Raymer's experimental $F_{\text {WIND }}$ values for four tested trees are shown with manually superimposed trendlines in Figure 7. Raymer noted that the four sets vary because $A$ varied among the four trees. Reported $F_{\text {WIND }}$ and $C_{D}$ values for the largest Raymer tree (R4) were used with Equation 7 to solve for an approximate reference $A$ (i.e., for $V=0$ ) for that tree.

$$
A=\frac{F_{W I N D}}{\frac{\rho}{2}\left(V^{2}\right)\left(C_{D}\right)}
$$

This reference $A$ was used first with $V^{2}$ and Raymer's $C_{D}$ values and then with $V$ and a constant $C_{D}$ in Equation 1 to calculate $F_{\text {WIND }}$ values for comparison to Raymer's experimental values. These estimated $F_{\text {WIND }}$ values and their trendlines are also shown in Figure 7.

Grace agreed with Raymer that the curves of Raymer's $F_{\text {WIND }}$ values, shown in Figure 7, are "linear." It is clear in Figure 7 that neither the slope nor the amplitude of the curve of actual $F_{\text {WIND }}$ values for Raymer's largest tree are described by Equation 1 using $V$, a constant reference $A$, and a constant $C_{D}=1.0$. It is clear in Figure 7 that the curve for Raymer's largest tree is closely approximated by $F_{\text {WIND }}$ values found using Equation 1 with $V^{2}$, a constant reference $A$, and Raymer's actual $C_{D}$ values, which decreased with increasing $V$. As noted at Figure 5, $F_{\text {WIND }}$ values found using Equation 1 with $V$ and a constant reference $A$ can be forced to fit the curve of actual $F_{\text {WIND }}$ values by employing $C_{D}$ values with no relationship to conventional reference data. The curves of $C_{D}$ values used in Equation 1 with $V$ and $V^{2}$ and a constant reference $A$ to describe Raymer's actual R4 $F_{\text {WIND }}$ values are compared in Figure 8.

Figure 7 suggests that "linear," as used by Grace and Raymer at least, describes a "straight line" shape (constant rate of change) in $F_{\text {WIND }}$ with increasing $V$ rather than a slope associated with a velocity exponent of 1 and fixed $C_{D}$. It is clear from lines R1-R4 in Figure 7 that the slopes of actual $F_{\text {WIND }}$ curves over $V$ may vary and could not all be described by a single $V$ exponent unless $C_{D}$ is varied for each. It is also clear in Figure 7 that this "linear" relationship was observed for a range of $V$ below the limit of crown reconfiguration.

\section{The Drag Equation Does Not Describe a Curve}

Perhaps the most basic argument against using $V$ rather than $V^{2}$ in the drag equation in order to describe a "linear" drag curve over velocity is that the drag equation does not describe a curve at all. The drag equation solves for a single quantity or point $\left(F_{\text {WIND }}\right)$ given a single value of $V$. Vogel (1994 p. 90), in fact, explains that the drag equation "is most definitely not the equation for drag," and, as already noted above, "it's just a definitional equation that converts drag to drag coefficient and vice versa." It should now be clear from the preceding discussion that for a tree at any given value of $V$, actual $A$ and, hence, $C_{D}$ are likely to vary. The equation can be solved iteratively for a number of points that will describe a curve, but either actual $A$ or $C_{D}$ may vary in any interation as $V$ varies.

Recent research (Alben et al. 2002, 2004; Steinberg 2002) has proposed an equation (Equation 8) to calculate the drag on a simple, flexible body using the material characteristics of the body rather than an experimetally derived drag coefficient.

$$
\text { Drag }=\eta^{2} \int_{\text {fibre }}[\rho] d y=\eta^{4 / 3} \int_{-\eta^{2 / 3} / 2}^{+\eta^{2 / 3} / 2}\left(\frac{1}{2} K^{3}+K^{\prime \prime}\right) \frac{d Y}{d S} d S
$$

But even this complex form of equation solves for a single value of drag at a single value of $V$ (Shelley 2003). It does not describe a curve of drag values over a range of $V$. In this light, it would seem difficult to suggest that simply manipulating the velocity exponent in Equation 1 will do so. 


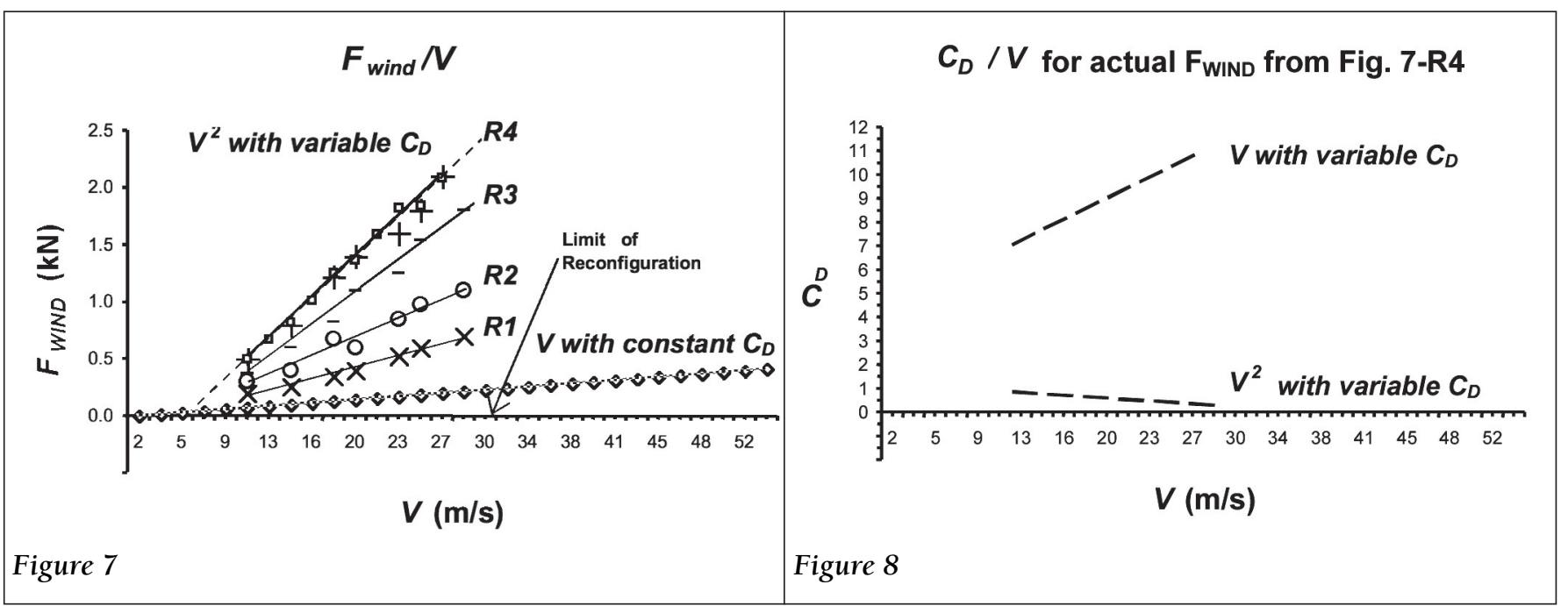

Figure 7. Lines R1-R4 show Raymer's experimental $F_{\text {WIND }}$ values for four trees as presented by Grace (1977). Raymer's $R 4$ values $(+)$ are closely approximated by $F_{\text {WIND }}$ values $(\square)$ calculated using Equation 1 with $V^{2}, \rho=1.2$ $\mathrm{kg} / \mathrm{m}^{3}$, constant reference $A$ (approximating reference $A$ for $\mathrm{R} 4$ using Equation 7 ), and Raymer's approximate $C_{D}$ values for $R 4$, which decrease with increasing $V$. The lowest line shows $F_{\text {WIND }}$ values calculated using Equation 1 with $V, \rho=1.2 \mathrm{~kg} / \mathrm{m}^{3}$, constant reference $A$ (approximating reference $A$ for $R 4$ using Equation 7 ), and constant $C_{D}$ (here $=1.0)$.

NOTES:

1. The curve of $F_{\text {WIND }}$ values found using $V^{2}$ with constant $A$ and $C_{\mathrm{D}}$ as shown in the preceding figures is not shown here; the scale is changed and more clearly shows the relationship of the "linear" curve to the $\mathbf{x}$ axis.

2. Raymer's experimental reference $A$ for $R 4$, which is approximated in the lines calculated with $V^{2}$ and $V$, varies from the arbitrary reference $A$ used in the preceding figures.

Figure 8. The lower line shows $C_{D}$ values used with Equation 1 and $V^{2}, \rho=1.2 \mathrm{~kg} / \mathrm{m}^{3}$, and constant reference $A$ (approximating reference $A$ for $R 4$ using Equation 7 ) to approximate Raymer's actual $R 4 F_{\text {WIND }}$ values. The upper line shows $C_{D}$ values used with Equation 1 and $V, \rho=1.2 \mathrm{~kg} / \mathrm{m}^{3}$, and constant reference $A$ (approximating reference $A$ for $R 4$ using Equation 7 ) to approximate Raymer's actual $R 4 F_{\text {WIND }}$ values. The large difference between $C_{D}$ values derived with $V^{2}$ and $V$ is apparent.

\section{CONCLUSIONS}

\section{The Most Appropriate Exponent}

The conventional form, $V^{2}$, is most appropriate for estimating $F_{\text {WIND }}$ with the drag equation in risk management of urban or landscape trees. Although using a "linear" form, $V$, may be useful in some other specific applications, the conventional form is not inappropriate, per se.

\section{Factors Supporting the Use of $\mathbf{V}^{\mathbf{2}}$}

- The drag equation solves for a single value of drag $\left(F_{\text {WIND }}\right)$ at a given velocity $(V)$ and is not intended to describe a curve.

- It is not clear from existing research when or if a "linear" relationship between drag $\left(F_{\text {WIND }}\right)$ and velocity (V) exists.

- If the actual relationship between $\operatorname{drag}\left(F_{\text {WIND }}\right)$ and velocity $(V)$ varies as something other than the square of $V$, any such variation is reflected in variation of the drag coefficient $\left(C_{D}\right)$, which is simply a ratio of conventionally defined and actual forces. A curve of $F_{\text {WIND }}$ values found using the conventional form of drag equation with $V^{2}$ would only be "expected" to vary purely as the square of $V$, as shown in Figure 1 , if $C_{D}$ is assumed to be constant. $F_{\text {WIND }}$ values are properly estimated using the conventional form of drag equation with $V^{2}$ and appropriately varied values of $C_{D}$.

- If the actual relationship between $\operatorname{drag}\left(F_{\text {WIND }}\right)$ and velocity $(V)$ varies "more linearly" than as the square of $V$, it is likely to be over the range of $V$ subject to crown reconfiguation. A conventional $V^{2}$ or "less linear" relationship may exist at higher values of $V$.

- Application of engineering safety standards to urban tree risk management requires estimation of drag $\left(F_{\text {WIND }}\right)$ for velocities $(V)$ beyond the apparent limit of crown reconfiguration where the conventional $V^{2}$ relationship is more likely to apply. 
- Procedurally, estimation of drag $\left(F_{W I N D}\right)$ using the drag equation requires the use of a drag coefficient $\left(C_{D}\right)$ from reference data. Such $C_{D}$ data are typically derived using the conventional $V^{2}$ which requires their use with the conventional $V^{2}$.

- Procedurally, $V^{2}$ is conventional in engineering standards for estimating $F_{W I N D}$, which may be applicable to tree risk management. Design wind velocities specified in these standards are likewise determined using $V^{2}$.

- Procedurally, $V^{2}$ is conventional in the arrangement of terms known as "dynamic pressure" (q), which may be specified in building codes or engineering standards that may be applied to tree risk management.

\section{LITERATURE CITED}

Alben, S., M. Shelley, and J. Zhang. 2002. Drag reduction through self-similar bending of a flexible body. Nature 420:479-481. www.math.nyu.edu/faculty/shelley/ papers/ASZ2002.pdf (accessed 1/3/05).

- 2004. How flexibility induces streamlining in a two-dimensional flow. Physics of Fluids 16(5):16941713. math.nyu.edu/faculty/shelley/papers/ ASZ2004.pdf (accessed 1/3/05).

Alaoui, A.S., G. Foret, and H. Bossuat. 1999. Wind stability analysis of urban trees (Analyse de la stabilité au vent des arbres), pp. 279-287. In Lemattre, M., P. Lemattre, and F. Lemaire (Eds.). Proceedings of an International Symposium on Urban Tree Health, Paris, 22-26 Sept. 1997, Acta Horticulturae 496.

American Society of Civil Engineers (ASCE). 1999. Wind loads, chapter 6. In Minimum Design Loads for Buildings and Other Structures (ASCE 7-98). American Society of Civil Engineers, Reston, VA. 330 pp. 2003. Wind loads, chapter 6. In Minimum Design Loads for Buildings and Other Structures (SEI-ASCE 7 02). American Society of Civil Engineers, Reston, VA.

Babitsky, S. 2004. Report writing: Stating your opinions and conclusions in a defensible manner. Arboric. Consult., Summer:6-7.

Baker, C.J. 1995. The development of a theoretical model for the windthrow of plants. J. Theoret. Biol. 175:355372.

Baker, C.J., and H.J. Bell. 1992. Aerodynamics of urban trees. J. Wind Eng. Indus. Aerodyn. 44(4):2655-2666.

Bell, H.J., A.R. Dawson, C.J. Baker, and C.J. Wright. 1990. Tree stability (paper 13), pp. 94-101. In Bulletin 97, Forestry Commission, Edinburgh, Scotland.

Benson, T. 2001a. Beginner's guide to aerodynamics: Bernoulli's equation. In Learning Technologies Project (LTP). NASA, John H. Glenn Research Center, Cleveland, OH. www.grc.nasa.gov/WWW/K-12/ airplane/bern.html (accessed 1/3/05). 2001b. Beginner's guide to aerodynamics: The drag coefficient. In Learning Technologies Project (LTP). NASA, John H. Glenn Research Center, Cleveland, OH. www.grc.nasa.gov/WWW/K-12/airplane/dragco.html (accessed 1/3/05).

_. 2001c. Beginner's guide to aerodynamics: Newton's laws of motion. In Learning Technologies Project (LTP). NASA, John H. Glenn Research Center, Cleveland, OH. www.grc.nasa.gov/WWW/K-12/airplane/newton.html (accessed 1/3/05).

_- 2001d. Beginner's guide to aerodynamics: The drag equation. In Learning Technologies Project (LTP). NASA, John H. Glenn Research Center, Cleveland, OH. www.grc. nasa.gov/WWW/K-12/airplane/drageq.html (accessed 1/3/05).

Bonser, R.C.H. 2001. Personal communication.

Bonser, R.C.H., and A.R. Ennos, 1998. Drag reconfiguration in seedling and mature larch, Larix europea $\times$ L. japonica. Abstract of unpublished paper, The Society for Experimental Biology Annual Meeting, 22-27 Mar. 1998, University of York.

Brudi, E. 2004. A new approach to tree safety assessment. Presentation at annual conference of the American Society of Consulting Arborists, 2 Dec. 2004, Phildelphia, PA.

Brudi, E., and P. van Wassenaer. 2002. Trees and statics: Nondestructive failure analysis. In Smiley, E.T., and K.D. Coder (Eds.). Proceedings of the Tree Structure and Mechanics Conference, 14-16 Oct. 2002. Savannah, GA. International Society of Arboriculture, Champaign, IL. www.tree-consult.org/images/pdf/eng/ brudi_trees_and_statics.pdf (accessed 1/3/05).

Coder, K.D. 1996. Tree Risk Management and Hazard Assessment: A General Overview. University of Georgia School of Forest Resources Extension Publication FOR 96-033.

_ 2000. Tree Biomechanics Series. University of Georgia School of Forest Resources Extension Publications FOR00-13 to 32 (index at warnell. forestry.uga.edu/warnell/service/library/index. php3?docID=413\&docHistory\%5B\%5D=2 (accessed $1 / 4 / 05)$.

Coutts, M.P., and J.Grace (Eds.). 1995 Wind and Trees. Cambridge University Press, Cambridge, UK. 501 pp.

Cullen, S. 2002a. Guying a large tree: Decision making and design (the Bedford protocol), pp. 139-155. In Smiley, E.T., and K.D. Coder (Eds.). Proceedings of the Tree Structure and Mechanics Conference, 14-16 Oct. 2002. Savannah, GA. International Society of Arboriculture, Champaign, IL.

_ 2002b. Trees and wind: A bibliography for tree care professionals. J. Arboric. 28(1):41-51. www.treelink.org/joa/2002/jan/06Cullen.pdf (accessed 1/3/05). 
2002c. Trees and wind: Wind scales and speeds. J. Arboric. 28(5):237-242. www.treelink.org/joa/2002/ sep/06Cullen.pdf (accessed 1/3/05).

- 2003. The wind drag equation and trees: A practical consideration of the velocity exponent. Paper presented at 4th International Plant Biomechanics Conference, 20-25 Jul. 2003, Michigan State University, East Lansing, MI.

Denny, M.W. 1994. Extreme drag forces and the survival of wind and water swept organisms. J. Exper. Biol. 194(1):97-115. http://jeb.biologists.org/cgi/reprint/194/ 1/83 (accessed 1/3/05).

Ennos, A.R. 1999. The aerodynamics and hydrodynamics of plants. J. Exper. Biol. 202:3281-3284.

Ezquerra, F.J., and L.A. Gil. 2001. Wood anatomy and stress distribution in the stem of Pinus pinaster Ait. Investigación Agraia: Serie Sistemas y Recursos Forestales 10(1):165-177. Instituto Nacional De Investigación y Tecnología Agraria y Alimentaria (I.N.I.A.), Ministerio de Ciencia y Tecnología Espania, Madrid. www.inia.es/gcontrec/pub/ ezque_1049878778696.pdf (accessed 1/3/05).

Fraser, A.I. 1962. Wind tunnel studies of the forces acting on the crowns of small trees. Report on Forestry Research, Forestry Commission, Edinburgh, Scotland.

Gaffrey, D., and O. Kniemeyer. 2002. The elasto-mechanical behaviour of Douglas fir, its sensitivity to tree-specific properties, wind and snow loads, and implications for stability-A simulation study. J. For. Sci. 48(2):49-69.

Gardiner, B.A., H. Peltola, and S. Kellomäki. 2000. Comparison of two models for predicting the critical wind speeds required to damage coniferous trees. Ecol. Model. 129:1-23.

Grace, J. 1977. Plant Response to Wind. Academic Press, New York, NY.

Grant, P.F., and W.G. Nickling. 1998. Direct field measurement of wind drag on vegetation for application to windbreak design and modeling. Land Degrad. Devel. 9(1):57-66.

Haritos, N., and K. James. 1996. Tree cable loads during high winds: Part 1-Effect of wind excitation, chapter 26. In Australian Wind Engineering Society (Ed.). Session Proceedings, Australian Wind Engineering Society, 5th Workshop on Wind Engineering, 22-23 Feb/ 1996. Tanuda, SA.

Hedden, R.L., T.S. Fredericksen, and S.A. Williams. 1995. Modeling the effect of crown shedding and streamlining on the survival of loblolly pine exposed to acute wind. Can J. For. Res. 25:704-712.

Heisler, G.M., and D.R. DeWalle. 1988. Effects of windbreak structures on wind flow. Agric. Ecosyst. Environ. 22/23:41-69.
Hoag, D.L., R.B. Fridley, and J.R. Hutchinson. 1971. Experimental measurements of internal and external damping properties of tree limbs. Trans. ASAE 16:20-28.

Hygelund, B., and M. Manga. 2003. Field measurements of drag coefficients for model large woody debris. Geomorphology 51:175-185. www.seismo.berkeley. edu/ manga/paper59.pdf (accessed 1/3/05).

James, K. 2003a. Dynamic loading of trees. J. Arboric. 29(3):165-171. 2003b. Personal communication.

Jim, C.Y., and H.H.T. Liu. 1997. Storm damage on urban trees in Guangzhou, China. Landsc. Urban Plann. 38:45-59.

Johnson, R.C., G.E. Ramsey, and D.S. O'Hagen. 1982. Wind-induced forces on trees. ASME J. Fluids Eng.104:25-30.

Kerzenmacher, T., and B. Gardiner. 1998. A mathematical model to describe the dynamic response of a spruce tree to the wind. Trees Struct. Function 12(6):385-394.

Kouwen, N., and M. Fathi-Moghadam. 2000. Friction factors for coniferous trees along rivers. J. Hydraul. Eng. 126(10):732-740.

Lai, W. 1955. Aerodynamic crown drag of several broadleaf species. Interim Technical Report AFSWP-863. U.S. Department of Agriculture, Forest Service, Division of Forest Fire Research, September, Washington, DC.

Loudon, C. 1999. How is fluid mechanics taught to biologists? In Proceedings of the 3rd ASME/JSME Joint Fluids Engineering Conference, 18-23 July. 1999, San Francisco, CA. FEDSM99-6828. ASME, New York, NY. www.people.ku.edu/ loudon/Assets/Pdf\%20documents/ 1999Fluid.pdf (accessed 1/3/05).

Lonsdale, D. 1999 Principles of Tree Hazard Assessment and Management. HMSO, London, UK.

Matheny, N.P., and J.R. Clark. 1994. A Photographic Guide to the Evaluation of Hazard Trees in Urban Areas, Second Edition. International Society of Arboriculture, Champaign, IL.

Mattheck, C., and K. Bethge. 2000. Simple mathematical approaches to tree biomechanics. Arboric. J. 24(4):307326.

Mattheck, C., and H. Breloer. 1994. The Body Language of Trees, A Handbook of Failure Analysis. HMSO, London, UK.

Mehta, K.C., and D.C. Perry. 2001. Guide to the Use of the Wind Load Provisions of ASCE 7-98. American Society of Civil Engineers, Reston, VA. 152 pp.

Mayhead, G.J. 1973. Some drag coefficients for British forest trees derived from wind tunnel studies. Agric. Meteorol. 12:123-130.

Mayhead, G.J., J.B.H. Gardiner, and D.W. Durrant. 1975. A Report of the Physical Properties of Conifers in Relation 
to Plantation Stability. Unpublished report of the Forestry Commission Research and Development Division, Edinburgh, Scotland.

Moore, J.R., and D.A. Maguire. 2002. The mechanics of trees under wind loading, pp. 39-50. In Smiley, E.T., and K.D. Coder (Eds.). Proceedings of the Tree Structure and Mechanics Conference, 14-16 Oct. 2002. Savannah, GA. International Society of Arboriculture, Champaign, IL.

Niklas, K.J. 1992. Plant Biomechanics: An Engineering Approach to Plant Form and Function. University of Chicago Press, Chicago, IL.

- 2002. Wind, size, and tree safety. J. Arboric. 28(2):84-93.

- 2003. Personal communication, April 23.

Niklas, K.J., F. Molina-Freaner, C. Tinoco-Ojanguren, and D.J. Poalillo. 2002. The biomechanics of Pachycereus pringlei root systems. Am. J. Bot. 89(1):12-21.

Peltola, H., S. Kellomäki, H. Väisänen, and V.-P. Ikonen. 1999. A mechanistic model for assessing the risk of wind and snow damage to single trees and stands of Scots pine, Norway spruce and birch. Can. J. For. Res. 29:247-661.

Peltola, H., B. Gardiner. S. Kellomäki, T. Kolström, R. Lässig, J. Moore, C. Quine, and J.-C. Ruel (Eds.). 2000. Special Issue: Wind and Other Abiotic Risks to Forests. For. Ecol. Manage. 135(1-3).

Pokorny, J. 2003. Urban Tree Risk Management: A Community Guide to Program Design and Implementation. NA-TP-03-03. USDA Forest Service, Northeastern Area, State and Private Forestry, St. Paul, MN. 194 pp.

Raymer, W.G. 1962. Wind resistance of conifers. NPL Aero. Rept. 1008.

Robertson, A. 1987. The use of trees to study wind. Arboric. J. 11:127-143.

Roodbaraky, H.J., C.J. Baker, A.R. Dawson, and C.J. Wright. 1994. Experimental observations of the aerodynamic characteristics of urban trees. J. Wind Eng. Indus. Aerodyn. 52:171-184.

Sauer, F.M., W.L. Fons, and K. Arnold. 1951. Experimental Investigation of Aerodynamic Drag in Tree Crowns Exposd to Steady Wind, Conifers. U.S. Department of Agriculture, Forest Service, Division of Forest Fire Research, Washington, DC.

Shelley, M. 2003. Personal communication.

Shi-Igai, H., and T. Maruyama. 1988. Measurement of wind drag forces on trees. J. Natural Disaster Sci. 10(2):25-33.

Sinn, G., and L. Wessolly. 1989. A contribution to the proper assessment of the strength and stability of trees. Arboric. J. 13(1):45-65.

Smiley, E.T. 2000. Personal communication.

Smiley, E.T., A. Key, and C. Greco. 2000. Root barriers and windthrow potential. J. Arboric. 26(4):213-217.
Spatz, H.-C., and F. Bruechert. 2000. Basic biomechanics of self-supporting plants: Wind loads and gravitational loads on a Norway spruce tree. For. Ecol. Manage. 135(1-3):33-44.

Standards Australia. 1989. AS 1170.2-1989 Minimum Design Loads on Structures and Amdt. 1-1991, Amdts. 2-3, 1993 (SAA Loading Code-Wind Loads). Standards Australia, Sydney, Australia.

Steinberg, V. 2002. Hydrodynamics: Bend and survive. Nature 420:473.

Tirén, L. 1926. Nágra undersokningar över stamformen (Some research on tree stem form).

Skogsvárdsforeningens Tidskrift 24(1-2):23-88 [in Swedish].

_. 1928. Einige untersuchungen uber die schaftform. Meddelanden Fran Statens Skogsforsoksanstalt, Hafte 24 5(4):81-152 [in German].

Vogel, S. 1989. Drag and reconfiguration of broad leaves in high wind. J. Exper. Bot. 40:941-948.

_ 1994. Life in Moving Fluids: The Physical Biology of Flow (2nd ed.). Princeton University Press, Princeton, NJ.

- 1996. Blowing in the wind: Storm-resisting features of the design of trees. J. Arboric. 22(2):92-98.

Wessolly, L. 1995. Fracture diagnosis of trees: Part 3Boring is no way for reliable fracture diagnosis. Stadt und Gruen (9):635-640.

Wessolly, L., and M. Erb. 1998. Handbüch der Baumstatik und Baumkontrolle. Patzer-Verlag, Berlin, Germany.

Wood, C.J. 1995. Understanding wind forces on trees, pp. 133-164. in Coutts, M.P., and J. Grace (Eds.). Wind and Trees. Cambridge University Press, Cambridge, UK.

Acknowledgments. I am grateful to Prof. Karl Niklas, Cornell University, for his review of a draft of the original, researchoriented paper (Cullen 2003); to Dr. John Moore, Forest Research New Zealand, for input on his review of the Mayhead and Hoag data and on the mathematics involved in deriving drag coefficients; to Prof. Michael J. Shelley, The Courant Institute, New York University, for his input on Equation 8; to Mr. Ken James, Burnley College, University of Melbourne, for his review of a draft of the original paper and for input on the Australian Wind Loading Standard; to Dr. Richard Bonser, Silsoe Institute and Prof. A. Roland Ennos of the University of Manchester, for their input on drag coefficient decrease rates; and to Dr. Tom Smiley, Barttlett Tree Research Laboratories, for comment on his research findings. Two anonymous reviewers provided useful comments. I am also indebted to Prof. Steven Vogel, Duke University, for his lucid explanation of the drag equation in Life in Moving Fluids.

Consulting Arborist

P.O. Box 31152

Greenwich, Connecticut, 06831, U.S.

dscottcul@att.net 
Résumé. Les arboriculteurs et les forestiers urbains sont de plus en plus concernés par la gestion des risques associés aux arbres. L'équation de tirage aérodynamique est potentiellement un outil de gestion efficace. Certaines sources questionnent la forme de l'équation - spécifiquement l'exposant de la vélocité - qui doit être appliquée pour les arbres. Pour le gestionnaire de risque, sensible à la sécurité du public et les questions légales, cela est plus qu'un curiosité académique. Lincertitude à propos de l'exposant approprié à utiliser remet en question la fiabilité de la formule conventionnelle. Cet article fait une revue de la littérature, des rapports sur la modélisation des deux formules d'équation et conclut que la formule conventionnelle - force du vent au carré - est appropriée pour les arbres. Une analyse détaillée est présentée pour le chercheur ou le praticien avancé. Une explication sommaire est fournie pour le praticien typique.

Zusammenfassung. Arboristen und Stadtforstleute sind in wachsendem Ausmaß über das Baumrisikomanagement betroffen. Die aerodynamische Zuggleichung ist ein potentiell sehr wertvolles Management-Instrument. Einige Quellen hinterfragen die Form der Gleichung - besonders den Velozitätsexponenten, der auf die Bäume angewendet werden soll. Für die Risikomanager, die mit der Sicherheit der Öffentlichkeit und der Haftung betraut sind, ist diese Frage mehr als eine akademische Kuriosität. Unsicherheit über den richtigen Exponenten stellt die Vertrauenswürdigkeit der konventionellen Form in Frage.

Resumen. Los arboristas y los dasónomos urbanos están aumentando su preocupación sobre el manejo de riesgos de los árboles. La ecuación aerodinámica es una herramienta de manejo potencialmente útil. Algunas fuentes cuestionan la forma de la ecuación - específicamente, el exponente de velocidad - que debería ser aplicado a los árboles. Para el manejador de riesgos de los árboles, preocupado con la seguridad del público y los aspectos legales, esto es más que una curiosidad académica. La incertidumbre acerca del exponente apropiado cuestiona la legitimidad de la forma convencional. Este reporte revisa la literatura sobre el modelamiento de la ecuación, y concluye que la forma convencional - velocidad al cuadrado - es apropiada para los árboles. Se presenta un análisis detallado para el investigador o practicante avanzado; se proporciona un resumen para el practicante típico 